Portland State University

PDXScholar

\title{
Variation in Female and Male Dialogue in Buffy the Vampire Slayer. A Multi-dimensional Analysis
}

Amber Morgan Sanchez

Portland State University

Follow this and additional works at: https://pdxscholar.library.pdx.edu/open_access_etds

Part of the Applied Linguistics Commons

Let us know how access to this document benefits you.

\section{Recommended Citation}

Sanchez, Amber Morgan, "Variation in Female and Male Dialogue in Buffy the Vampire Slayer. A Multidimensional Analysis" (2020). Dissertations and Theses. Paper 5582.

https://doi.org/10.15760/etd.7454

This Thesis is brought to you for free and open access. It has been accepted for inclusion in Dissertations and Theses by an authorized administrator of PDXScholar. Please contact us if we can make this document more accessible: pdxscholar@pdx.edu. 
Variation in Female and Male Dialogue in Buffy the Vampire Slayer:

A Multi-dimensional Analysis

by

Amber Morgan Sanchez

A thesis submitted in partial fulfillment of

the requirements for the degree of

\author{
Master of Arts \\ in \\ Teaching English to Speakers of Other Languages
}

Thesis Committee:

Susan Conrad, Chair

Kimberley Brown

Alissa Hartig

Portland State University

2020 
Abstract

Media representations of gender often reflect normative societal beliefs about gender and have the ability to both reinforce and subvert those beliefs. The current study examines the linguistic characterization of male and female characters on the television show Buffy the Vampire Slayer, a series with an overt feminist message. Previous studies of gender variation in dramatic dialogue have found that female characters tend to be portrayed as using more linguistic features associated with an interpersonal and emotional focus (involvement), while male characters are portrayed as using more features centered on the transfer of information. Previous research has also found that female writers show a stylistic preference for more interpersonal, involved speech, while male writers show a preference for more informational speech. The goal of this thesis was to determine whether female and male dialogue on Buffy differed in terms of the use of the features of involvement and whether female and male scriptwriters portrayed female and male characters in different ways. A corpus of dialogue from the show was compiled for this study and analyzed using multi-dimensional analysis, a technique within corpus linguistics that allows researchers to examine multiple linguistic features simultaneously. The results of the analysis revealed that female language on the show used significantly more features of involvement than male language and that female and male scriptwriters portrayed the characters highly consistently. Interestingly, the use of features of involvement was often portrayed on the show as a powerful form of selfexpression, confidence, and empathy that corresponds with the show's main theme of female empowerment. Although there were strong patterns, there was also variability 
within the female and male dialogue that corresponded to the context of interactions and the social relationships between characters. The results highlight the need for more studies of gender representation in the media that focus on language use and the importance of curricula that help learners develop the ability to critically evaluate popular media. 


\section{Acknowledgements}

I would like to express my deepest gratitude to the members of my thesis committee, Dr. Susan Conrad, Dr. Alissa Hartig, and Dr. Kimberley Brown, for their insightful feedback and assistance throughout this process. I especially wish to thank my committee chair, Dr. Susan Conrad, without whose guidance and support this research would not have been possible. Your expert knowledge, enthusiasm for this project, and generosity with your time are greatly appreciated. I am also immensely grateful to all of those who have contributed to the James R. Nattinger Scholarship fund. The financial support from this scholarship allowed me the freedom to focus on my academic work and complete this thesis. 
Table of Contents

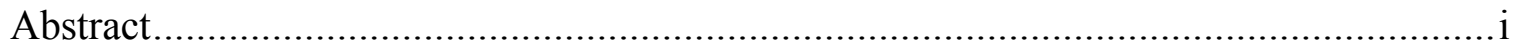

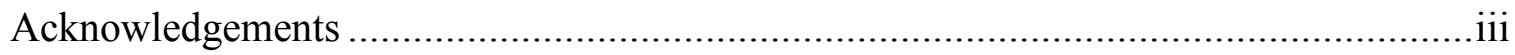

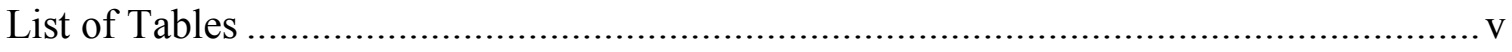

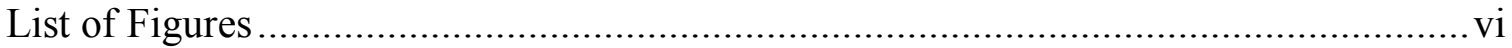

Chapter 1: Introduction.................................................................................... 1

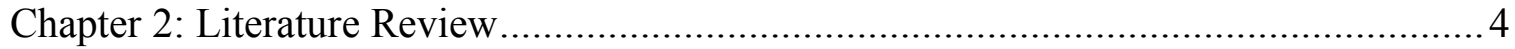

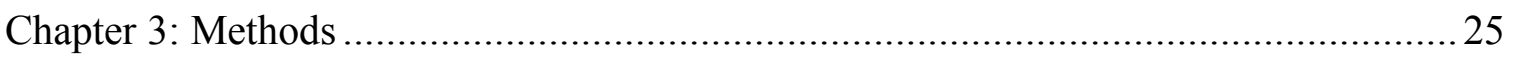

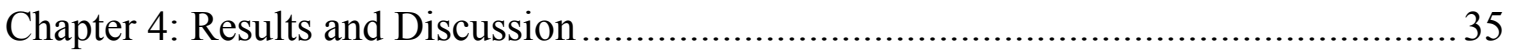

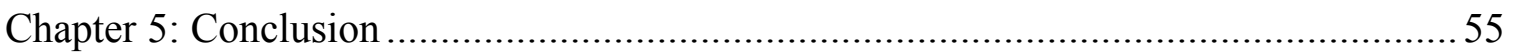

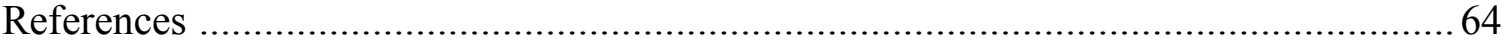


List of Tables

Table 2.1 Linguistic Features of Dimension 1: Involved vs.

Informational Production ................................... 12

Table $3.1 \quad$ Number of Episodes in the Buffy Corpus by Season and Gender ....28

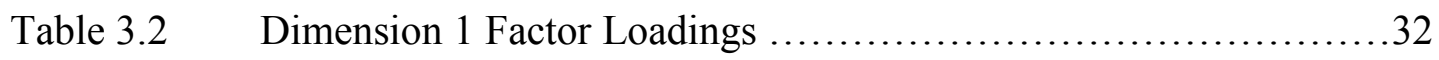

Table 4.1 Results of the Two-way ANOVA Examining the Effect of

Character Gender and Scriptwriter Gender on Buffy Dialogue ..... 40 
List of Figures

Figure 2.1 Mean Scores of Registers Along Dimension 1: Involved vs.

Informational Production .........................................13

Figure 2.2 Mean Dimension 1 Scores of Overall Female and Male

Language in Star Trek .............................................14

Figure 4.1 Dimension 1 Mean Scores for Female and Male Language

in Buffy the Vampire Slayer .........................................36

Figure 4.2 Range of Dimension 1 Scores for Male and Female

Language in Buffy the Vampire Slayer .............................49 


\section{Chapter 1: Introduction}

I was nine years old when Buffy the Vampire Slayer made its television debut and sixteen years old by the time the finale aired seven seasons later. In a sense then, I grew up with Buffy. Mesmerized by the first episode, I faithfully tuned in every subsequent week for the show's entire run. As the title implies, Buffy fights vampires, so on one level it is a supernatural adventure story. At its heart though, Buffy the Vampire Slayer is a coming of age tale centered on a strong female protagonist. Yes, Buffy kicks ass, but she also struggles with academics, dating, her parents' divorce, and the social politics of high school. She also faces serious trauma and grief. Her character is allowed to make mistakes and even be unlikable at times, a level of complexity often reserved for male characters. Buffy is a distinctly feminine hero who battles the forces of evil while wearing heels and uses her emotional intelligence and vulnerability to solve problems as often as she uses violence.

As a young girl, seeing traits that are typically associated with femininity represented in a positive light in a character who embodies leadership and strength was very influential for me and helped jumpstart my interest in feminism. Re-watching the series years later from the vantage point of someone who has survived young adulthood, I was surprised to find myself even more moved by the triumphs and travails of the “Scooby Gang," as Buffy and her friends call themselves. As a student of linguistics, I also became more interested in the distinctive, witty dialogue and complicated gender dynamics on the show. 
Within the social sciences, gender is widely viewed as a social construct rather than an inherent biological characteristic (Lorber, 2011). Women and men learn to perform their gender roles through the process of socialization. As the predominant transmitter of cultural information and social values, language is an important factor in the socialization process and thus in the construction of gender roles (Lorber, 2011). For decades sociolinguists have examined the role of gender in the relationship between language and society. One major area of focus within sociolinguistic research on language and gender has been differences in the way that women and men use language (see Coates, 1993; Holmes, 1995; Lakoff, 1973; Tannen, 1991).

Analyses of popular media, such as television, can be a useful way of exploring gender variation in language because media representations of women and men reflect social attitudes on gender. Television dialogue is of course not the same as naturally occurring speech; however, corpus-based studies have shown that it often shares many of the core linguistic features found in conversation (Quaglio, 2009; Al-Surmi, 2012). Beyond its similarities to real speech, television dialogue is also of interest because it represents the way that scriptwriters believe women and men talk. Examinations of dramatic dialogue can therefore reveal perceived differences in the speech of men and women, which can shed light on underlying assumptions about their roles in society.

This study uses a corpus linguistics approach to examine the dialogue of male and female characters on the television series Buffy the Vampire Slayer. The show's creator, Joss Whedon, promoted the series as an explicitly feminist work, a claim that feminist and media scholars have debated at length (Byers, 2003; Levine, 2007). Buffy aired from 1997 to 2003, and attracted a large viewership, particularly among young women. The 
series tells the story of Buffy Summers, a teenage girl who is the latest in a line of young women chosen by fate to battle vampires and other forces of evil. She initially wishes she could live a normal life, but eventually grows to embrace her role as the Slayer. This study analyzes the differences in male and female language portrayed on the show, taking into account the role of scriptwriter gender, in order to explore how the show's linguistic characterization of men and women fits into its stated aims as a feminist series and how it may subvert or promote gender stereotypes.

\section{A Note on Terminology and the Sex/Gender Binary}

This study adopts the framework of the social sciences that views gender as a social construct distinct from biological sex (Lorber, 2011). Gender is in essence a performance; it is the way women and men present themselves in the social world, learned through the process of socialization. Gender and biological sex do not necessarily correspond. That is, a person of the female sex may not identify as a woman and vice versa. This study is specifically interested in gender, not biological sex. When I use the terms male and female in the current study, I am referring to gender although they are also the accepted terms used to describe biological sex. Linguistics studies that examine gendered language typically use the terms female and male in the way that I use them here, so I am choosing to remain consistent with previous research in the field. The process I used to determine the gender of characters and screenwriters is covered in the methods chapter. 


\section{Chapter 2: Literature Review}

This chapter provides background for the study, emphasizing the importance of considering multiple linguistic features in characterizations of gendered speech and the need to expand sociolinguistic inquiries of gender variation in the realm of pop culture, and providing details about the Buffy TV series. Section 2.1 first provides a summary of sociolinguistic research on gender variation in language, starting with earlier qualitative studies and moving into more recent studies that utilize corpus techniques. Then, in 2.2 , I explain how linguists have used multi-dimensional analysis, a method within corpus linguistics, to explore gender variation in fictional dialogue. Section 2.3 then directs the focus to a discussion of sociolinguistics and pop culture, focusing on the role that studies foregrounding language use in popular media can play in helping to promote more equitable media representations of gender. Finally, in 2.4 I provide background on Buffy the Vampire Slayer and previous academic work related to the show, and in 2.5 conclude with a statement of purpose and research questions for the current study.

\subsection{Gender Variation in Language}

Studies have consistently reported differences in men and women's language use. Lakoff's (1973) pioneering publication, Language and Woman's Place, argued that societal expectations regarding appropriate behavior for men and women are reflected in the way that they speak and that these gendered speech patterns are used as a means of denying women access to power. This sparked a great deal of research on gendered speech, which led sociolinguists to make several generalizations about female and male 
language. First, women's speech appeared to center more on interaction and social relationships, while men's speech was generally more information oriented and factual (Holmes, 1995; Tannen, 1991). Tannen (1991) referred to this distinction as rapport vs. report. She also observed that women and men utilize different involvement strategies in conversation (Tannen, 1990). Involvement refers to the interpersonal, social nature of discourse. The women in Tannen's study showed more involvement in their conversations by validating one another's choice of topic by asking questions and expressing agreement. The men introduced new topics frequently rather than responding to the topics raised by other speakers. Another observation was that women's language was often more tentative than that of men, employing more hedges, modals, and other features (Lakoff, 1973). These early studies were largely qualitative with small sample sizes and some reliance on researchers' intuition about women and men's speech, which made their generalizability questionable, but they were important in stimulating the field of gender-related language variation.

After several decades of research on gender variation in language use, it is now possible to see four major perspectives in the research: the deficit approach, the dominance approach, the difference approach, and the social constructionist approach (Coates, 2015). Lakoff's (1973) work falls into the deficit approach because it treats male language as the norm to which female language is compared and found lacking. Lakoff describes women's speech as weak and unassertive due to the use of features such as hedges. Although her work served as a catalyst for studies of gender and language, this view has since been widely criticized for its implications that women's speech in 
intrinsically inferior and that women should strive to emulate male speech (Coates, 2015).

The dominance approach views women as an oppressed social group and considers differences in male and female speech to be manifestations of unequal power relations between men and women. Much of this research focuses on how male dominance and female subordination is enacted through language use (Coates, 2015). West and Zimmerman (1983) were early proponents of this perspective. In an analysis of mixed-gender conversations they found that men initiated the vast majority of interruptions, which they interpreted as a way of asserting control over the conversation in an enactment of masculine power.

Rather than focusing on power as the source of gender variation in language, the difference approach proposes that women and men belong to different subcultures and have thus been socialized to speak in different ways. This framework explicitly does not interpret gendered patterns in women's speech as manifestations of powerlessness, but instead highlights the ways that women use different linguistic strategies (Coates, 2015). Tannen is a major advocate of the difference approach, as exemplified by her work on the different "involvement strategies" that men and women use in conversation. The difference approach has been criticized, mainly by proponents of the dominance approach, for not taking unequal power relations between men and women into account. Tannen, however, has argued that the distinction between the two approaches is based on a false dichotomy, as hierarchical power structures influence the diverging language socialization that men and women experience (Kendall \& Tannen, 2001). 
The most recent approach is the social constructionist approach, which builds upon the previous perspectives and emphasizes the notion that gender is not a static trait but rather a social construct that is accomplished through interaction (Coates, 2015). In this view, gendered speech patterns exist outside of the speaker and are tied to culturespecific gender ideologies. Speakers can then use these gendered patterns as an interactional resource that indexes feminine or masculine self-presentation (Kendall \& Tannen, 2001). For example, Hall (1995) examined ways in which phone-sex workers utilized gendered discourse to construct a feminine identity in their occupation. Gendered discourse can also act as a constraint on speakers. Bergvall (1996) analyzed small group discussions at a university and found that a female student who used both "assertive" speech patterns typically associated with men and "cooperative" speech patterns typically associated with women was negatively evaluated by her peers when they perceived her speech as assertive. The conception of gendered speech as both a resource and a constraint helps to account for the variance seen in language use both between and within genders. Social constructionists argue that social and interactional context is essential to analyses of gendered language use because speakers draw on different linguistic resources to meet varying interactional goals (Kendall \& Tannen, 2001).

While many of the findings from early studies of gendered language have been questioned because they relied on small sample sizes and often tried to make generalizations about all male and female speech rather than speech within specific contexts, researchers have continued to examine many of the same linguistic features using new techniques. Corpus-based approaches have been utilized to build on earlier studies and lend support for some of their conclusions. Corpus approaches make it 
feasible to analyze larger samples and see patterns of interactions among a more diverse group of speakers, thus making findings more generalizable. Rayson, Leech, and Hodges (1997) argued for the potential of using corpus techniques to answer sociolinguistic questions, which they demonstrated with a lexical frequency analysis of women and men's speech using data from a demographically sampled subcorpus of the British National Corpus. They found that women were more likely to use personal pronouns, proper nouns, and verbs while men were more likely to use common nouns, which supports the hypothesis that women's speech is more interpersonal and men's speech is more informational. Another analysis of over 14,000 texts pulled from previous studies on gender differences in language use confirmed that women were more likely to use pronouns, especially first person singular, and hedges, as well as emotion words and people's names (Newman, Groom, Handelman, \& Pennebaker, 2008). Murphy's (2010) study on gender variation in Irish-English conversation also found that women hedged significantly more than men.

This more recent research seems to indicate that some of the patterns sociolinguists have noticed are consistently present in women's and men's speech. However, while these corpus studies featured larger data sets, they generally only looked at around three to five linguistic features at a time, which still makes larger generalizations about gendered speech patterns questionable. Those that did examine more features did not look at how those features interact or the contexts in which they were used. Many sociolinguists have criticized studies of gendered language that fail to take into account the context of the interactions under analysis, pointing out that women and men alter their interaction style according to interlocutor and situation (Talbot, 2003). 
Studies that examine features in isolation and out of their social context may reach questionable conclusions. For instance, a study examining the use of a feature such as hedges may conclude that women are more tentative than men because they used more hedges. However, without examining a fuller range of features that women and men are using simultaneously it is difficult to make an overall characterization of gendered speech patterns. Women might be using hedges more, but also using other features that indicate directness.

\subsection{Analyzing Multiple Linguistic Features Simultaneously}

Since the 1970s, linguists studying register variation have argued for the importance of analyzing registers and styles in terms of the co-occurring linguistic features that characterize them over a narrow focus on isolated features (see Brown \& Fraser, 1979; Ervin-Tripp, 1972; Hymes, 1974). Brown and Fraser (1974) point out that a concentration on specific features in isolation can be misleading without also taking into account systematic variation involving the co-occurrence of sets of features. Chafe (1982) and Tannen (1985), in their work on variation between spoken and written language, identified several dimensions of variation among texts. For example, they both noted that texts can vary in terms of their degree of focus on interpersonal involvement. Texts that are highly focused on interpersonal involvement are characterized by certain co-occurring linguistic features that function to build rapport and express emotion, such as first and second person pronouns and hedges. On the other end of that dimension are texts that focus on the transfer of information rather than involvement, which is accomplished with features such as passives and nominalizations. A conversation among friends would 
likely fall on the highly involved end of the continuum, while an academic text would likely fall on the highly informational end.

\subsubsection{Multi-dimensional Analysis}

While Chafe (1982) and Tannen (1985) identified the sets of linguistic features in their analyses on an intuitive basis, Biber (1988) developed an empirical approach for identifying sets of linguistic features that have a tendency to co-occur in texts based on statistical analysis. Since this approach involves many steps, I first provide background on multi-dimensional analysis generally, before explaining its use in studies of gender variation in language.

Multi-dimensional analysis (MD) is a technique used within corpus linguistics that allows researchers to describe and compare a wide range of registers. Biber's (1988) original MD study examined the use of 67 linguistic features in 23 registers of spoken and written English. Using factor analysis, Biber identified groups of features that tend to occur together in texts. Based on the idea that features co-occur because they work together to perform related communicative functions, the sets of features are then interpreted as dimensions of variation. A dimension is thus a continuum along which texts vary. Biber identified seven dimensions of variation, which have been used in subsequent MD studies to characterize and compare additional registers (Conrad \& Biber, 2001). MD analysis has since been used to analyze languages other than English, such as Korean (Kim and Biber, 1994), Spanish (Biber, Davies, Jones, \& Tracy-Ventura, 2006), and Brazilian Portuguese (Sardinha, Kauffman, \& Acunzo, 2014), as well as many discourse domains in English, such as science research articles (Kanoksilapatham, 2007), 
civil engineering writing (Conrad, 2018), university spoken and written registers (Biber, 2006), World English spoken and written registers (Xiao, 2009), internet and pre-internet registers (Sardinha, 2014), and pop songs (Bertoli-Dutra, 2014). The variety in these studies illustrates the usefulness of MD analysis to explore a range of linguistic questions, from pedagogical to sociolinguistic.

Dimension 1 represents a fundamental distinction in many registers and languages and involves more features than any other dimension. It characterizes texts along a continuum that ranges from 'Involved Production,' which is highly interactive and affective and features generalized content, to 'Informational Production,' which is carefully planned and features dense integration of information. Different sets of linguistic features co-occur at either end of the continuum. Involved production is characterized by the use of first and second person pronouns, present tense verbs, private verbs (such as think), contractions, wh questions, possibility modals, and others. Informational production, on the other hand, is characterized by the use of lexical nouns, longer words, prepositions, attributive adjectives, and agentless passives, among others (Conrad \& Biber, 2001). The name of Dimension 1, Involved vs. Informational Production, reflects the earlier work by Chafe (1982) and Tannen (1985) that established involvement as a term for describing discourse that is interpersonal in focus. Table 1 depicts the full range of features associated with Dimension 1, grouped according to whether they indicate involved or informational production. 
Table 2.1

Linguistic Features of Dimension 1: Involved vs. Informational Production

\begin{tabular}{|c|c|}
\hline Involved Production & $\underline{\text { Informational Production }}$ \\
\hline $\begin{array}{l}\text { private verbs } \\
\text { that deletions } \\
\text { contractions } \\
\text { present tense verbs } \\
\text { second-person pronouns } \\
\text { do as pro-verb } \\
\text { analytic negation } \\
\text { demonstrative pronouns } \\
\text { general emphatics } \\
\text { first person pronouns } \\
\text { pronoun it } \\
\text { be as main verb } \\
\text { causative subordination } \\
\text { discourse particles } \\
\text { indefinite pronouns } \\
\text { general hedges } \\
\text { amplifiers } \\
\text { sentence relatives } \\
\text { wh questions } \\
\text { possibility modals } \\
\text { non-phrasal coordination } \\
\text { wh clauses } \\
\text { final prepositions } \\
\text { adverbs }\end{array}$ & $\begin{array}{l}\text { nouns } \\
\text { word length } \\
\text { prepositions } \\
\text { type/token ratio } \\
\text { attributive adjectives } \\
\text { place adverbials } \\
\text { agentless passives } \\
\text { past participial } \\
\text { postnominal clauses }\end{array}$ \\
\hline
\end{tabular}

Figure 1 shows where various registers fall along Dimension 1. Those at the bottom with the lowest dimension scores, such as academic prose, represent the most informational registers. Those at the top with the highest dimension scores, such as face to face conversation, represent the most involved registers. 
Involved
Production

Informational

Production

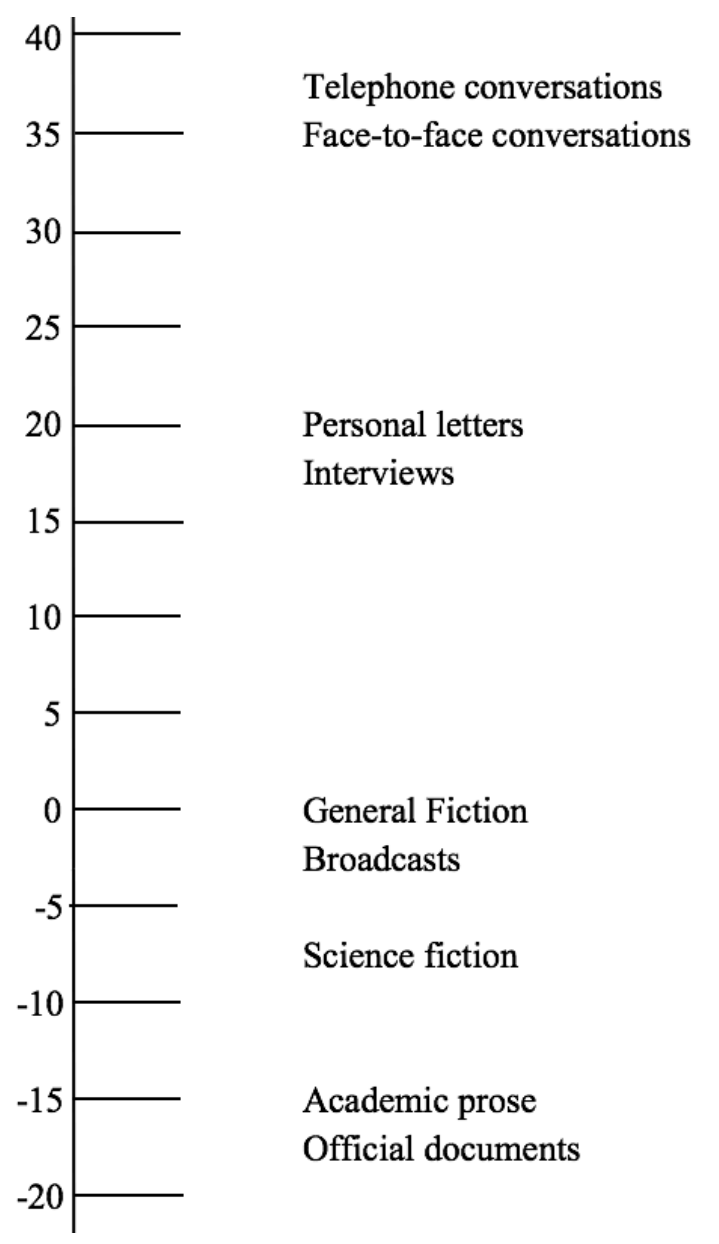

Figure 2.1 Mean scores of registers along Dimension 1: Involved vs. Informational Production (Conrad and Biber, 2001).

\subsubsection{Studies of Gender Variation in Fictional Dialogue Using Multi-dimensional Analysis}

Two studies have employed multi-dimensional analysis to analyze gender variation in fictional dialogue. Rey (2001) analyzed the speech of male and female characters on the television show Star Trek, including episodes from three different series and three movies from 1966 to 1993, along Dimension 1. Rey chose to look at Dimension 1 because the features on opposite ends of the continuum correspond to the characterization of women's speech as having more features of involvement and men's speech as more 
informational that other studies have reported. She conducted both synchronic and diachronic analyses, looking at how portrayals of women and men on Star Trek evolved over time. The synchronic analysis revealed significant differences between overall male and female language on the show, with female language portrayed as having more features of involvement than male. Figure 2 features the mean Dimension 1 scores for overall male and female language with reference to other registers.

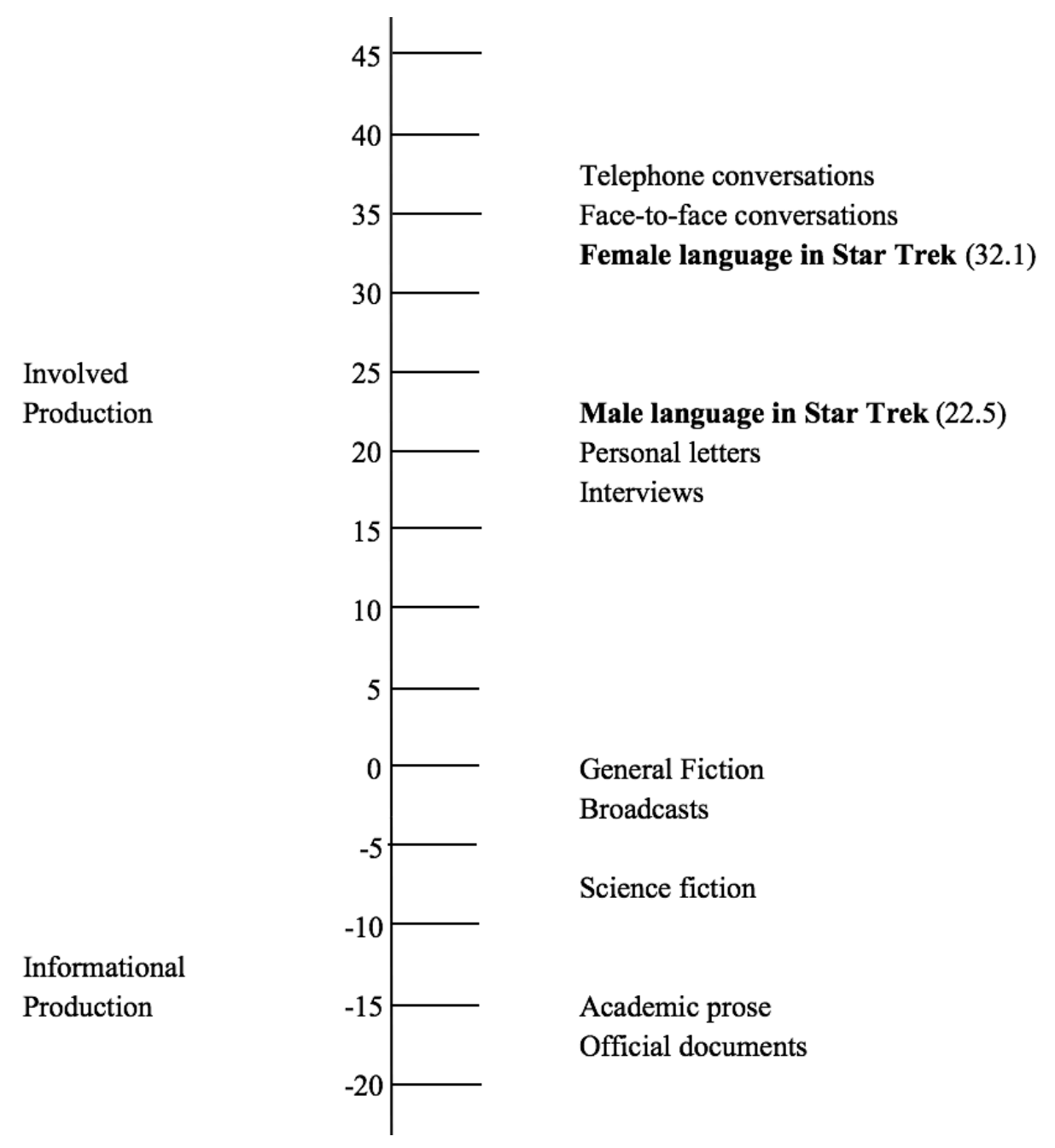

Figure 2.2 Mean Dimension 1 scores of overall female and male language in Star Trek (Rey, 2001). 
The diachronic analysis revealed that in the original series (1966) women's speech was drastically more involved than men's. However, by the final series included in the study (1993) this pattern actually reversed and women's speech became more informational while men's became more involved. The following scene from the classic Star Trek episode 'The Trouble with Tribbles' (1967) exemplifies the linguistic characterization of women in the original series. Lieutenant Uhura is visiting a pub on a space station where she witnesses the barkeeper arguing with Cyrano Jones, a galactic trader. The barkeeper insists he is not interested in purchasing any goods and Jones responds by showing him a tribble (a small, fuzzy creature).

[M] Jones: But I have something better. I have something from the far reaches of the galaxy. Surely you want... [pulls tribble out of his pocket]

[M] Bar: Not at your price.

[F] Uhura: Oh, what is it? Is it alive? May I hold it? Oh, it's adorable! What is it?

[M] Jones: What is it? Why, lovely lady, it's a tribble.

[F] Uhura: A tribble?

[M] Jones: Only the sweetest creature known to man.

[F] Uhura: Listen! It's purring!

[M] Jones: It's only saying that it likes you.

[F] Uhura: Are you selling them?

[M] Bar: That's what we're trying to decide right now. [The two men bargain for a moment.] 
[M] Bar: Alright, I'll double my offer. Two credits.

[M] Jones: Twice nothing is still nothing.

[F] Uhura: Well, if you're not gonna take him, I'm gonna take him. I think he's cute.

[The men bargain some more and finally settle on six credits a tribble. The barkeeper turns to Uhura with Jones' tribble and says:]

[M] Bar: That will be ten credits.

[M] Jones: That happens to be my sample and I'll do with it as I please. And I please to give it to the lovely little lady here.

[F] Uhura: Oh, I couldn't... could I?

[M] Jones: I insist.

Rey notes that while the focus of the scene is on Uhura's desire to buy the tribble, she says much less than the men. Further, her dialogue has a high concentration of the features associated with involved production, specifically contractions (it's, you're, couldn't), first and second person pronouns, and be as a main verb (what is it, is it alive, it's adorable). Although the language the male characters use also includes some features of involvement, it is more balanced with features of informational production as well, particularly prepositions, nouns, and attributive adjectives (from the far reaches of the galaxy, to the lovely little lady, sweetest creature). The use of these features works to portray the men's interaction as a business transaction in which they bargain and exchange information with one another, while Uhura's response is portrayed as primarily emotional. 
By the final series included in the study, Star Trek: Deep Space Nine (1993), male dialogue included more features of involvement and women's dialogue actually become more informational than men's. The transition in dialogue reflects a transition in the roles that male and female characters on the show filled. In Deep Space Nine, several of the main male characters are fathers who are shown to be very involved in parenting their children and many of the main female characters are in positions of authority in which they often relay information and give orders. Rey interpreted this shift as evidence of changing societal gender roles, as women and men are able to take on characteristics more traditionally associated with the opposite gender.

The ability to look at multiple features at once with MD analysis is crucial to Rey's study, as an investigation into only one or two features would not have allowed for the same level of detailed comparison between male and female language on the show. For example, if a researcher looked at the use of first person pronouns in male and female dialogue on the show they would find that they occur often in the speech of both men and women, but more frequently in women's speech. But without also considering the occurrence of features of informational production, such as nouns and attributive adjectives, the researcher would miss the way that male speech is represented as more balanced between involved and informational production in the original series. An examination of the full range of features on Dimension 1 allowed Rey to discuss how the features work together to portray male and female speech in very different ways.

The second study to utilize MD analysis to examine gender variation in fictional dialogue was conducted by Biber and Burges (2001). Like Rey, they were also interested in examining language change over time. They wanted to look for evidence of changing 
historical patterns of gendered language use and opted to use fictional dialogue as data primarily to account for the lack of naturally occurring speech data from earlier time periods. They chose to use a subcorpus of plays written from 1650 to 1990, taken from the ARCHER corpus (Biber \& Finegan, 1993). In their analysis, the researchers considered three different parameters: the gender of the author, the gender of the speaker, and the gender of the addressee. They conducted a multidimensional analysis, which allowed them to compare female and male speech (according to both author gender and gender of speaker in relation to addressee) over time and compare the patterns with those found in previous qualitative studies of gendered language. Overall they concluded that women were represented as more involved and tentative than men, but that there was a general trend for all speech to become more involved over time. This trend appeared to be related to ideas about how men and women interact in mixed gender settings. In the seventeenth century texts, addressee gender was the most significant factor related to involvement, as dialogue addressed to women was found to be the most highly involved. However, in the twentieth century texts, the determining factor became whether dialogue was cross-gender or same-gender. Cross-gender discourse became more highly involved overall, while discourse among characters of the same gender was only moderately involved.

To my knowledge, Biber and Burges' (2001) study is the only one that explores the effect of author gender on differences in male and female character's speech. First, they noted that both male and female authors showed a preference for speakers of their own gender in terms of the amount of speaking time. Male authors in particular gave male characters significantly more dialogue, almost $70 \%$ of the text in nineteenth and 
twentieth century plays. Male authors also strongly preferred to pair male speakers with male addressees, favoring mixed gender pairings the least. Female authors, on the other hand, were much more equitable in their pairings, commonly portraying women speaking to both men and other women.

They also found a striking difference in the perceptions of involvement between male and female authors. Female authors portrayed all speakers as using more features of involvement than male authors did, a difference that was especially apparent in the dialogue of male characters. Female authors also represented mixed gender discourse as extremely involved regardless of the gender of the speaker, while male authors portrayed female characters speaking to males with a high level of involvement, but males speaking to females with only a moderate level of involvement. Biber and Burges (2001) argued that these findings partially support the claims made in earlier studies of gendered language use that women generally use more features of involvement and are more tentative than men, given that the female characters' dialogue showed a higher level of involvement and the female authors showed a stylistic preference for involved speech overall. But they also note that these patterns appear to vary between mixed-gender and same-gender interactions. Their findings suggest that writer gender plays an important role in gender variation in fictional dialogue, but more research is needed beyond this one study.

\subsection{Sociolinguistics and pop culture}

Feminist scholars and researchers in pop culture and media studies have long considered analyses of gender representations in popular media, including television, to be crucial to 
our understanding of gender in contemporary society. Portrayals of women and men in pop culture not only reflect existing social attitudes about gender but they also construct and maintain normative notions of femininity and masculinity (Milestone \& Meyer, 2012). Although research in sociolinguistics tends to favor naturally occurring speech whenever possible, Lakoff and Tannen (1984) have argued that dramatic dialogue can also be a valuable data source in that it represents the writer's internalized model for conversation, which can reveal unconscious assumptions about language use.

We might assume that writers craft dialogue modeled to some degree on their own speech patterns. Indeed, Biber and Burges' (2001) study suggests that male and female authors write dialogue that aligns with the speech patterns associated with their own gender; that is, women's speech generally includes more features of involvement, thus women tend to write dialogue with a higher level of involvement and vice versa. However, it is also important to consider the way that internalized assumptions about gender might influence the way that authors portray men and women. Feminist critiques of pop culture often raise the question of who holds the power to control media representations of women and point out that it is frequently men who tell women's stories, which often has the result of privileging normative beliefs about women's role in society over women's voices and experiences (Lemish, 2012). If writers view women's role in society as more socially oriented than that of men, it would be reasonable to expect that ideology to shape their representation of women. Differing perspectives on gender is thus another factor that could potentially affect the way that male and female authors write dialogue for their characters. A pilot version of the current study found that male scriptwriters on Buffy the Vampire Slayer portrayed both women and men's speech 
with a higher level of involvement than did female scriptwriters (Sanchez, 2019). This finding contradicts previous research and suggests the need for further study.

Richardson (2010) points out that much research into pop-cultural texts is conducted from a media studies standpoint that often ignores the linguistic component almost entirely, instead centering on visual imagery. This leaves ample opportunity for sociolinguistic analyses of such texts that will focus on language use. Such studies can contribute to the growing conversation on the importance of media representation of women and minority groups and having more writers, directors, and producers from those groups creating media themselves.

\subsection{A Brief history of Buffy}

Given the issues that feminist scholars have identified with men controlling media portrayals of women, Buffy the Vampire Slayer makes an ideal candidate for a study on gender representation in media, as it is a series with a focus on female empowerment created by a man and written predominately by men. The show is a supernatural drama that focuses on the main character, Buffy Summers, and her friends, as she comes to terms with her role as the Slayer. Buffy is a reluctant hero who initially longs to lead a normal life as a teenage girl rather than fight the forces of evil. However, as the narrative progresses Buffy comes to embrace her Slayer identity while simultaneously navigating the challenges of adolescence and young womanhood.

Despite the supernatural content, Buffy is known for its exploration of real issues facing young adults, such as bullying, sexuality, sexual assault, growing up in a single parent household, and transitioning from high school to college life. Joss Whedon, the 
show's creator, has described the central concept of the show as "high school as a horror movie" (Said, 2010). Buffy thus uses supernatural elements as a metaphor for adolescent anxieties and trauma. Wilcox and Lavery (2002), academics who specialize in pop culture, explain that on the show teenage problems are represented by literal monsters, for example a strict new stepfather who turns out to be a machine programmed to kill or a boyfriend who transforms into a monster after he and his girlfriend have sex.

The issues explored in the series were often controversial and highly socially relevant. Whedon has stated that he intended to create a show that would subvert gender norms and challenge horror tropes that portray women as powerless. The character Buffy Summers was meant to invert the formula endemic to horror movies of a small, blond, vulnerable girl wandering into a dark alley and getting killed, by instead turning her into a hero (Billson, 2005). Buffy was envisioned as a celebration of female power that calls into question traditional notions of femininity and masculinity. However, some critics have noted that Buffy tends to fight evil in revealing outfits and becomes increasingly blond as the series progresses, visual elements that seem to play to the male gaze (Wilcox \& Lavery, 2002). Whedon himself has claimed that he did not believe "Buffy the Lesbian Separatist" would appeal to audiences and therefore he aimed to promote female empowerment "in a fun, disarming fashion" (Said, 2010).

Given the topics that the show examines and its explicitly feminist orientation, it is perhaps unsurprising that Buffy the Vampire Slayer has inspired a huge body of scholarship. Hundreds of academic articles about Buffy have been published, featuring a wide variety of analyses, including the show's contested portrayal of female power, whether Buffy represents third wave or postmodern feminism, and the show's 
representations of race and sexual identity (see Byers, 2003; Levine, 2007; Ono, 2000). Adams (2003) studied the use of slang in Buffy, creating a glossary of Buffyisms and examining the role of slang on the show as an outlet for Buffy to express her personality when her role as Slayer constrains her. In 2008 “Buffy studies” became more official when a group of academics formed the Whedon Studies Association, an organization that took over the publication of a peer-reviewed journal of Buffy scholarship called Slayage that is freely available online (Whedon Studies Association, 2019). The majority of the studies published in Slayage focus on the show's treatment of gender, sexuality, sexual orientation, or race. Several look at the language used on the show in various ways, including analyses of non-standard perlocutionary acts in the episode "Hush," in which the characters lose the ability to speak and must communicate non-verbally (Jenkins and Stuart, 2003) and the use of Latin as the Lingua Franca of magic (Lester, 2014). A special issue published in 2006 focused on pragmatics, discourse, and style on Buffy (Adams, 2006).

\subsection{The Current Study}

The current study seeks to expand on research into pop culture from a sociolinguistic perspective by using a corpus-based approach to compare the speech of male and female characters on Buffy the Vampire Slayer and to compare the role of the gender of the scriptwriter in that portrayal. Since the show focuses on female empowerment, it is possible that the female characters speak in ways that contradict stereotypical gendered speech patterns. The context of a single TV show with multiple authors provides a unique opportunity to examine the effects of author gender on 
dialogue, as the authors are striving for consistency among characters across episodes. Given that previous corpus studies utilizing MD analysis have found substantial differences between male and female dialogue along Dimension 1 (Biber \& Burges, 2001; Rey, 2001), which contrasts involved versus informational production, this study will focus on Dimension 1. The features that characterize this dimension also correspond to those that have consistently been found to differentiate gendered speech patterns. Within the context of a show with an explicitly feminist orientation that aims to promote gender equity, an investigation of the way that male and female writers represent the speech of men and women can help us to understand underlying ideologies regarding modern gender roles and whether men and women view them differently.

The purpose of the present study is to explore the linguistic characterization of female and male characters on the show Buffy the Vampire Slayer and the role of scriptwriter gender in their representations, in order to contribute to our understanding of gender representation in the media and how portrayals of men and women can challenge or perpetuate gender norms. Specifically, I will address the following research questions:

1. Is there a difference in the use of features associated with involvement between female and male language in Buffy the Vampire Slayer?

2. Do female and male scriptwriters portray female and male language differently on Buffy the Vampire Slayer with regard to the use of features associated with involvement? 


\section{Chapter 3: Methods}

This section details the methodology employed in this study. I begin in Section 3.1 by introducing the scriptwriters who worked on Buffy the Vampire Slayer and the writing process they used to create the show. In 3.2 I then describe the corpus of Buffy dialogue that was compiled for the analysis and the steps of its preparation. Lastly, in Section 3.3, I explain the data analysis procedures used in the study.

\subsection{The Context of the Show}

The series Buffy the Vampire Slayer aired for seven seasons with a total of 144 episodes, first on the WB television network and later on UPN. It premiered in March 1997 and concluded in May 2003. During its run, the show regularly reached between four and six million viewers (Wahoske, n.d.). Buffy developed a loyal following among girls and young women up to age 34, who made up the majority of viewers (Early, 2004).

While Joss Whedon conceived of the concept for the show, he worked with a team of writers to create each episode (Espenson, n.d.). The fan website Buffy World features an episode index that lists the episodes in each season along with the writers and directors. In total, 25 writers are credited throughout the series' run, including eighteen men and seven women. Men wrote the majority of the episodes at $58 \%$, while women wrote $33 \%$, and mixed gender teams of authors wrote $9 \%$. The writers on the show are public figures who typically have personal websites, social media accounts, or biographical entries on websites such as the International Movie Database (IMDB). For the purposes of this study, I determined writer gender based on information from these 
sources, such as the use of gendered pronouns in autobiographical entries on the writers' personal websites.

Jane Espenson, a writer and producer on Buffy, has explained the writing process for the show in detail (Espenson, n.d.). A team of writers would begin with a general idea for an episode and a main character, often decided by Whedon. Collectively, the writers decided on the central theme and plot of the episode, breaking the story down into different acts and scenes on a whiteboard. When this was done, the individual credited author of the episode used this material to create an outline which was then submitted to the showrunner. Showrunners are in charge of managing the production of television shows and have the ultimate authority over a show's creative direction. Joss Whedon served as the showrunner on Buffy during seasons one through five, while Marti Noxon took on the role during the last two seasons. After reviewing notes from the showrunner, the author then wrote several drafts of the full script, making adjustments based on the showrunner's comments. At times, the production schedule would require a pair of authors to work on the same episode together, in which case the authors would divide the episode up and write separate portions. According to Espenson, this practice did not produce disjointed scripts as one might imagine, because the writers had "all learned to write in the same style" (Espenson, n.d., para. 9).

\subsection{The Corpus}

I compiled a Buffy corpus specifically for use in this study. The approximately 230,000 word corpus is composed of the scripts for 50 episodes of Buffy the Vampire Slayer, including episodes from all seven seasons. Female and male authors are equally 
represented in the corpus to allow for comparison between them. The relatively small size of the corpus is necessary due to issues of practicality, given the extensive formatting required to prepare each text. While it would be ideal to include every episode of the show in the corpus, at 50 out of 144 episodes - over a third of the show - it is large enough to conduct meaningful analyses.

\subsubsection{Episodes in the Corpus}

Episodes were selected for inclusion in the corpus based on two criteria: season in the series and scriptwriter gender. For each season of the show, I included an equal number of episodes written by men and women. For seasons two to seven, four episodes written by men and four written by women were included, for a total of eight episodes per season. Season one features only one episode written solely by a woman, so in order to maintain gender balance in the corpus only two episodes from season one were included. Episodes written by mixed gender teams of authors were excluded. All seasons are 22 episodes long with the exception of season one, which has 12 episodes. I used a random number generator to select episodes for inclusion in the corpus based on episode number. For each season except season one, I generated episode numbers and selected the first four episodes written by women and the first four written by men that appeared. For season one, I included the sole episode written by a woman and one episode written by a man selected using the random number generator. Table 2 provides an overview of the texts that make up the corpus. 
Table 3.1

Number of Episodes in the Buffy Corpus by Season and Gender

$\begin{array}{lllllll}\text { Season } & \text { Year } & \begin{array}{l}\text { Number of } \\ \text { Episodes } \\ \text { by } \\ \text { Women }\end{array} & \begin{array}{l}\text { Number of } \\ \text { Words in } \\ \text { Episodes } \\ \text { by Women }\end{array} & \begin{array}{l}\text { Number of } \\ \text { Episodes } \\ \text { by Men }\end{array} & \begin{array}{l}\text { Number of } \\ \text { Words in } \\ \text { Episodes by } \\ \text { Men }\end{array} & \begin{array}{l}\text { Total } \\ \text { of } \\ \text { Words }\end{array} \\ \text { One } & 1997 & 1 & 4,700 & 1 & 4,800 & \\ \text { Two } & 1997-1998 & 4 & 18,000 & 4 & 19,000 & \\ \text { Three } & 1998-1999 & 4 & 17,900 & 4 & 18,100 & \\ \text { Four } & 1999-2000 & 4 & 18,600 & 4 & 18,800 & \\ \text { Five } & 2000-2001 & 4 & 19,200 & 4 & 17,900 & \\ \text { Six } & 2001-2002 & 4 & 17,600 & 4 & 16,300 & \\ \text { Seven } & 2002-2003 & 4 & 20,300 & 4 & 19,100 & \\ \text { Total: } & & 25 & 116,300 & 25 & 114,000 & 230,300\end{array}$

The shooting scripts for the selected episodes were downloaded from the Buffy World website, which features the script for every episode in the series. There are multiple websites that feature transcripts of episodes compiled by fans as they watch the series. These transcripts report dialogue as spoken in the episodes, while the shooting scripts are the final version of the dialogue as written by the scriptwriter. Because the focus of the study is on differences in dialogue due to scriptwriter gender, I have chosen to use the shooting scripts as data as there may be instances in which the dialogue heard on the show differs slightly from what was written due to last minute changes such as actor adlibbing.

\subsubsection{Formatting and Coding}

The texts were formatted and coded so that they could be read by a computer. As this analysis is focused on character dialogue, any text in the scripts that was not dialogue, 
including titles, headings, and stage directions, was removed. Character names that precede dialogue were replaced with speaker tags that prevent the name from being counted in analysis while still allowing identification of the speaker. Each script was divided into two files, one for female speakers and one for male speakers, and coded by author gender. Characters were categorized as male or female based on the pronouns used to refer to them either by other characters or in stage directions. Many minor characters were also identified in the script in gendered ways, for instance Frenzied Girl or Fighting Boy. Non-human characters, such as vampires and monsters, were categorized in the same way. In cases where characters or the script referred to a supernatural entity using the pronoun it rather than he or she, the supernatural character's dialogue was excluded from the corpus because its gender could not be identified.

Corpus formatting also involves file naming conventions and header conventions. Each file in the corpus has a unique name that includes information about the show, season, episode, author gender, and speaker gender. In addition, all files feature a header at the beginning of the text that provides further information about the episode, including the filename, the title of the episode, the name of the author, the year the episode was written, and the characters featured in the episode.

Finally, each text was tagged for part of speech using the Biber Tagger (Biber, 1988, 2006). The tagger is a computer program that automatically identifies linguistic features in texts. This allows the use of a program that counts the occurrences of each feature in each text, which is necessary for conducting a multi-dimensional analysis. 
3.3 Data Analysis

As described in Chapter 2, multi-dimensional analysis is a well-established method within corpus linguistics that allows researchers to analyze and compare registers using a large number of linguistic features. By allowing researchers to see patterns of cooccurrence in texts, MD analysis provides a much fuller picture of a text's characteristics than analyses of isolated features. MD analysis has been used to analyze a wide and eclectic range of registers and varieties of language.

The current study uses Dimension 1, as identified by Biber (1988), to analyze variation in dialogue written by male and female authors on Buffy the Vampire Slayer. Dimension 1 ranges from highly involved production on one end, to highly informational production on the other. Texts with a high score on Dimension 1 have frequent occurrences of the linguistic features associated with involvement, while texts with a low Dimension 1 score have frequent occurrences of the features associated with the transfer of information. The features, introduced in chapter 2 , are reviewed again below.

A program designed to count the occurrences of linguistic features was used to calculate the normed counts of the features that characterize Dimension 1 in each tagged text. Normed counts were used rather than raw counts so that the differing lengths of the texts will not impact the analysis. Next, SAS software was used to calculate the dimension score for each text, as well as the mean dimension scores for the following categories: all male and all female dialogue, all dialogue written by men and all dialogue written by women, and each of the four possible combinations of writer and speaker (female writer female dialogue, female writer male dialogue, male writer female dialogue, male writer male dialogue). 
Dimension scores are calculated by summing the normed frequencies of the features that are associated with Dimension 1. As part of the factor analysis conducted in Biber's (1988) original study, the factor loading for each feature on a dimension was calculated. The factor loading is a number ranging from 0.0 (indicating no relationship) to 1.0 (indicating a perfect correlation) that reflects the extent to which a feature is representative of the underlying dimension. Factor loadings can be positive or negative due to the fact that Dimension 1 is made up of two groupings of features that occur in complementary distribution. When many features with positive loadings are present in a text, the features with negative loadings are less frequent, and vice versa. For each text and gender category listed above, the frequencies of features that have positive factor loadings on Dimension 1 (i.e. features of involvement) will be added up and then the frequencies of features that have negative factor loadings (i.e. features of informational production) will be subtracted to calculate the dimension score. The factor loadings for each feature associated with Dimension 1 are shown in Table 3 below. 
Table 3.2

Dimension 1 Factor Loadings (from Biber, 1988)

\begin{tabular}{|c|c|c|}
\hline \multirow[b]{2}{*}{$\underline{\text { Positive Features }}$} & Linguistic Feature & $\underline{\text { Factor Loading }}$ \\
\hline & private verbs & 0.96 \\
\hline & that deletions & 0.91 \\
\hline & contractions & 0.90 \\
\hline & present tense verbs & 0.86 \\
\hline & second-person pronouns & 0.86 \\
\hline & $d o$ as pro-verb & 0.82 \\
\hline & analytic negation & 0.78 \\
\hline & demonstrative pronouns & 0.76 \\
\hline & general emphatics & 0.74 \\
\hline & first person pronouns & 0.74 \\
\hline & pronoun it & 0.71 \\
\hline & be as main verb & 0.71 \\
\hline & causative subordination & 0.66 \\
\hline & discourse particles & 0.66 \\
\hline & indefinite pronouns & 0.62 \\
\hline & general hedges & 0.58 \\
\hline & amplifiers & 0.56 \\
\hline & sentence relatives & 0.55 \\
\hline & $w h$ questions & 0.52 \\
\hline & possibility modals & 0.50 \\
\hline & non-phrasal coordination & 0.48 \\
\hline & $w h$ clauses & 0.47 \\
\hline & final prepositions & 0.43 \\
\hline & adverbs & 0.42 \\
\hline \multirow[t]{8}{*}{$\underline{\text { Negative Features }}$} & nouns & -0.80 \\
\hline & word length & -0.58 \\
\hline & prepositions & -0.54 \\
\hline & type/token ratio & -0.54 \\
\hline & attributive adjectives & -0.47 \\
\hline & place adverbials & -0.42 \\
\hline & agentless passives & -0.39 \\
\hline & past participial postnominal clauses & -0.38 \\
\hline
\end{tabular}

As mentioned above, the dimension score for each text was calculated, as well as the mean dimension scores for the following categories: all male and all female dialogue, 
all dialogue written by men and all dialogue written by women, and each of the four possible combinations of writer and speaker (female writer female dialogue, female writer male dialogue, male writer female dialogue, male writer male dialogue). The scores were then plotted along Dimension 1 to show the variation and compared using statistical analysis to determine if there are significant differences between male and female dialogue on the show and dialogue written by men and women. A two-way ANOVA, or analysis of variance, was used to explore the effect of scriptwriter gender and character gender on the dialogue with regard to the use of features of involvement. This test allows researchers to analyze the effects of more than one variable at the same time and reveals not only whether there are differences in the dialogue according to author and character gender, but also if there is any interaction between them, for example if male writers portray female characters in a way that differs dramatically from how female writers portray them.

Finally, to supplement the MD analysis, I used MonoConc Pro concordance software to conduct tag searches for the linguistic features associated with Dimension 1, focusing on episodes that most clearly exemplified the quantitative findings. I also read the scripts for these episodes in order to find samples of dialogue that include clusters of multiple Dimension 1 features. This allowed me to analyze how the features are used in the texts and provide examples from the scripts to illustrate the findings of the MD analysis. While the study involves a great deal of quantitative analysis, this last step utilizes a more qualitative approach in order to explore how the use of the linguistic features associated with Dimension 1 relate to the larger themes of the show. This step is essential in answering the questions of whether male and female speech is different on 
the show and whether men and women portray them differently. Just as Rey (2001) showed how the features of involvement were used to represent women's speech on classic Star Trek as much more emotional than men's, I selected dialogue samples that show how the features under analysis work together to portray men and women in certain ways on Buffy and discuss how these portrayals contribute to or perhaps clash with the prominent themes on the show, such as gender equity and female empowerment. This qualitative analysis also allowed me to explore how contextual factors, such as the relationship between speakers and the topic of discussion, relate to speakers' use of the features of involvement. 


\section{Chapter 4: Results and Discussion}

In this chapter, I discuss the results of the multi-dimensional analysis and illustrate them with examples of dialogue from Buffy. First, in Section 4.1 I provide an overview of the results for the analysis of Buffy dialogue, considering both male and female characters' speech relative to previous MD studies. Section 4.2 the compares the male and female characters, providing an answer to the first research question of whether there are differences in male and female dialogue on the show with regard to the features of involvement and presenting examples of the overall linguistic characterization of the main male and female characters. Section 4.3 addresses the second research question, which asked whether male and female scriptwriters portrayed male and female characters in different ways. Section 4.4 highlights variability within male and female speech on Buffy and explores the contextual factors that influence it, such as the situation in the scene and the social relationships between characters. Finally, Section 4.5 provides a summary of the study's main findings.

\subsection{Overview of the Results of the Multi-dimensional Analysis}

The dialogue of both male and female characters fell on the involved end of Dimension 1. The female dialogue had a mean Dimension 1 score of 42.0 and the male dialogue a mean of 34.2. Before considering the differences by gender, it is worthwhile to consider both genders' use of involvement features relative to a wide range of discourse in English. Figure 4.1 shows the mean Dimension 1 scores for female and male language on Buffy 
the Vampire Slayer in relation to the mean Dimension 1 scores for Star Trek dialogue (Rey, 2001) and various registers from Biber's (1988) original study.

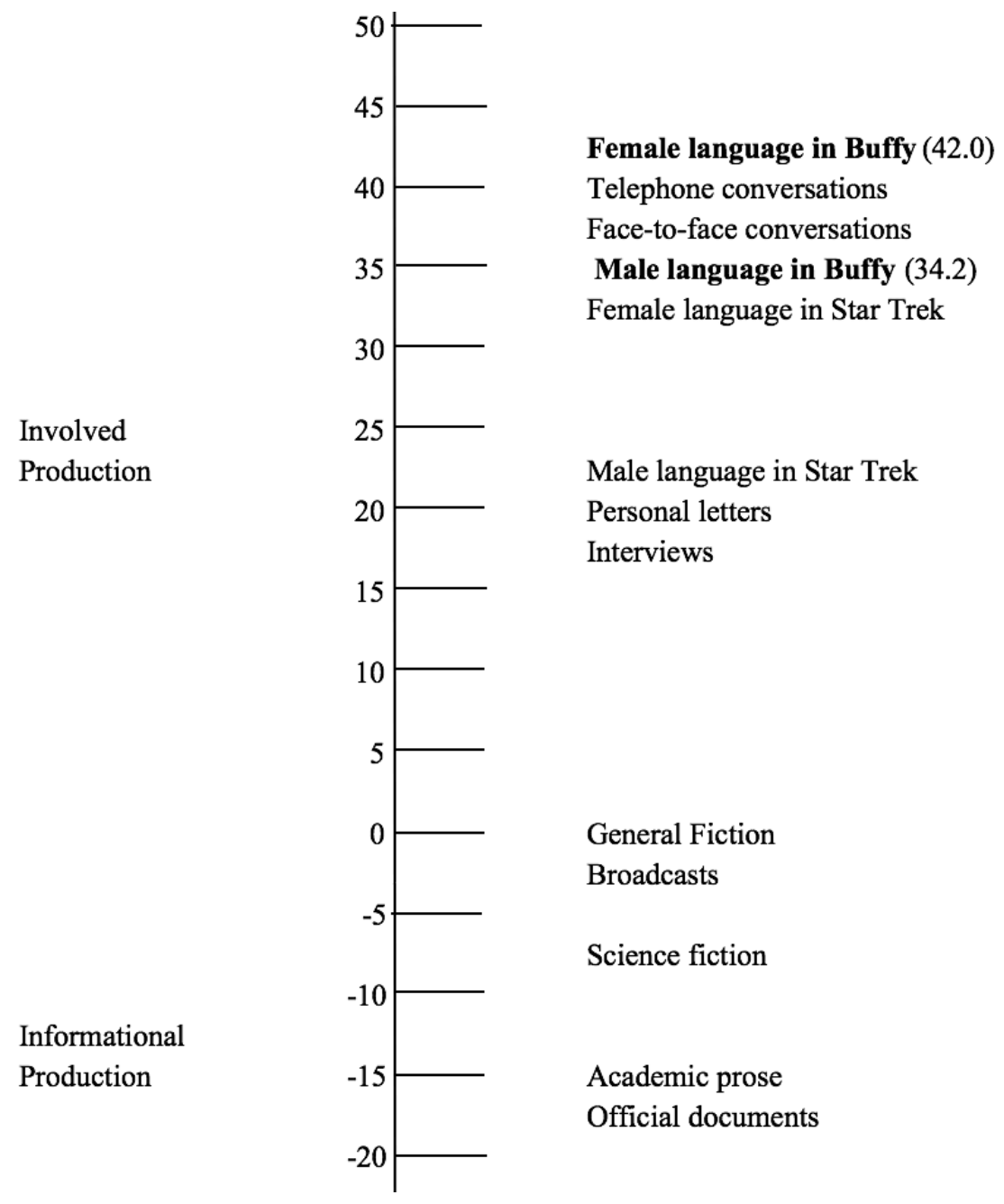

Figure 4.1 Dimension 1 mean scores for female and male language in Buffy the Vampire Slayer

It is not surprising that the dialogue on Buffy is on the involved end of the continuum, given that it is intended to imitate natural conversation which is a register that is characterized by a high level of the features of involvement. However, what is striking 
is how extreme the Dimension 1 scores are for Buffy dialogue. The male dialogue on Buffy has a higher Dimension 1 score than the overall female dialogue on Star Trek across various series, while the female dialogue on Buffy has a higher Dimension 1 score than both natural conversation and female dialogue from classic Star Trek (Rey, 2001). It is noteworthy that the female language in Buffy is more involved than the female language in a television show that aired in the 1960s, given Buffy's feminist orientation and Rey's (2001) conclusion that the shift over time in female language on Star Trek towards more informational production reflected a shift in societal gender roles. However, it is important to consider the social context in which the dialogue occurs. In Star Trek the majority of the main characters are adult coworkers involved in workplace interactions even if they also have personal relationships with one another, while most of the main characters on Buffy are teenagers involved in close friendships and romantic relationships.

The following scene from the episode "Band Candy" illustrates the highly involved, interpersonal nature of the discourse on the show. Buffy and her friends have just arrived at school and are chatting before class. She has just described a nightmare she had about taking the SAT and they offer to help her prepare for the exam. Linguistic features associated with involved production are in bold.

Oz: You know, Willow and I both took it last year. We could help you get ready. There's this whole trick to antonyms but... this isn't the place.

Willow: $\quad \mathrm{Oz}$ is the highest scoring person ever to fail to graduate. 
Buffy: Isn't she cute when she's proud?

Oz: $\quad$ She's always cute.

[Xander and Cordelia join them]

Willow: We could work on it tonight.

Xander: $\quad$ Work on what tonight?

Cordelia: Oh god, are we killing something again?

Buffy: $\quad$ Only my carefree spirit.

Oz: $\quad$ Buffy SAT prep.

Willow: Oz is helping. He's the highest scoring person-

Cordelia: We know. We did the impressed thing already.

Xander: I hate they make us take that thing. It's totally fascist, and personally, I think it discriminates against the uninformed.

Cordelia: Actually, I'm looking forward to it. I do well on standardized tests.

[The others stare at Cordelia]

Cordelia: What? I can't have layers?

Both the male and female characters in this scene use many features of involved production. The frequent use of the pronoun it, demonstrative pronouns (this isn't the place), and indefinite pronouns (are we killing something again) reflects the shared context of the characters. First and second person pronouns and present tense verbs signal the interpersonal nature of the dialogue, as the characters discuss what is currently happening and share their perspectives on it. Willow and $\mathrm{Oz}$ use the possibility modal 
could to offer Buffy help on the SAT (we could help you get ready, we could work on it tonight). The use of contractions and that deletions (I think it discriminates) reflects the informality of the situation and the effects of on-line production on discourse. The distinctive discourse style of the main characters in Buffy is characterized in part by taking the features of involvement that are typically seen in natural speech and exaggerating them, often to humorous effect. Teenage speech, in particular, is portrayed in this manner on the show, a pattern which is especially pronounced in female characters, as discussed in the next section.

\subsection{Differences in Female and Male Language in Buffy the Vampire Slayer}

The first research question asked if there is a difference in the use of features associated with involvement between male and female language on the show. As presented in the previous section, the female dialogue had a much higher mean score than the male dialogue (42.0 versus 34.2). The dialogue of both genders varied, but the range of scores in female dialogue was consistent with the female characters using more features of involvement (33.9-54.6 for female characters and 22.6-44.3 for male characters). Not surprisingly, the results of the two-way ANOVA revealed a statistically significant difference between the dialogue of male and female characters $(p<0.0001)$. Table 4.1 displays the results of the two-way ANOVA. The results for scriptwriter are discussed in the next section. 
Table 4.1

Results of the two-way ANOVA examining the effect of scriptwriter gender and character gender on Buffy dialogue

Variable

Scriptwriter gender

Character gender

Scriptwriter gender* Character gender

\section{DF Type I SS Mean Square F Value $\operatorname{Pr}>$ F}

$\begin{array}{lllll}1 & 8.43 & 8.43 & 0.29 & 0.5920\end{array}$

$\begin{array}{lllll}1 & 1501.59 & 1501.59 & 51.51<.0001\end{array}$

$\begin{array}{lllll}1 & 32.36 & 32.36 & 1.11 & 0.2947\end{array}$

As mentioned above, the female dialogue on the show was much more highly involved than the male dialogue. While the male characters used fewer features of involvement than the female characters, the male dialogue still fell on the involved end of Dimension 1 , very close to natural conversation. While the female dialogue was often quite extreme in its use of the features of involvement, in general the male dialogue reflected typical conversational use of involvement features.

Overall, the male characters use more features of informational production than the female characters. The following dialogue sample from the episode "No Place Like Home" is an example of typical male speech on the show. Anya, a former demon who is now a part of Buffy's group, struggles with human politeness norms and has just told a customer in Giles' magic shop to "please go" after ringing up her purchases. Xander steps in to explain how customer service interactions usually work. The features of informational production in Xander's speech are in bold. 
Xander: $\quad$ Anya, the Shopkeepers Union of America called? They want me to tell you "please go" just got replaced with "have a nice day." Anya: $\quad$ I have their money. Who cares what kind of day they have? Xander: $\quad$ No one. It's a long cultural tradition of raging insincerity. Embrace it.

As Xander is explaining conversational politeness norms, he uses many of the features of informational production, such as nouns (Shopkeepers Union, tradition), attributive adjectives (nice day, long cultural tradition, raging insincerity) and prepositions (of America, with "have a nice day"). He uses many features of involvement as well, but it is clear that his focus is conveying information to Anya. His use of informational features is also often used in a humorous manner, such as in his witty and detailed descriptions exemplified by his depiction of customer service as a long cultural tradition of raging insincerity.

The character Giles is an especially obvious example of a male character who makes more extensive use of the features of informational production. Giles, a middle aged British man who serves as Buffy's Watcher, at times speaks in a highly informational manner, though this is balanced by his use of more interpersonal speech as his fondness for Buffy and her friends grows. Tasked with training and guiding the Slayer, Giles acts as Buffy's mentor and, in later seasons especially, as a father figure. He is comically bookish and uses his encyclopedic knowledge of the occult to aid Buffy and her friends in their battles against evil. The following scene from "Becoming, Part 1" highlights Giles' more informational speaking style compared to his female interlocutors. 
Buffy's love interest, a vampire named Angel (also called Angelus) who previously did not harm people because he had a soul, has recently lost his soul and turned evil. He is plotting to summon a demon called Acathla and Giles has just discovered that Angel has stolen the artifact that is needed to summon him.

Giles: I've just been on the phone with the museum. The artifact in question is missing. And the curator has been murdered. Vampires.

Buffy: $\quad$ And we're sure this thing was the Tomb of Alfalfa?

Giles: $\quad$ Acathla. And yes, the information Kendra's Watcher has provided seems conclusive.

Willow: Okay, can somebody explain the whole 'he will suck the world into Hell' thing? That's the part I'm not loving.

Giles: $\quad$ The demon universe exists in a dimension separate from our own. With one breath Acathla will create a vortex, a kind of whirlpool that will pull everything on Earth into that dimension, where any non-demon life will suffer horrible, eternal torment.

Buffy: $\quad$ So that would be the literal kind of sucking into Hell. Neat.

Kendra: $\quad[$ to Buffy $]$ You think Angelus and the others are responsible for the theft of the tomb?

Buffy: I'd bet folding money on it.

Kendra: I can't believe you dated him. I mean, he's got to be stopped. 
All of the characters in the scene are discussing the problem they are facing with the demon Acathla, but the linguistic characterization is quite different between Giles and the female characters. Giles uses many of the features of informational production, such as nouns and prepositions (on the phone, in a dimension, with one breath), attributive adjectives (horrible, eternal torment), and agentless passives (the curator has been murdered) to inform the other characters of the demon. His speech is densely packed with lexical nouns in order to convey detailed information (the artifact in question, demon universe, non-demon life). The female characters in the scene, on the other hand, use far more of the features of involved production, including demonstrative pronouns, discourse particles (so, okay), contractions, and first and second person pronouns and private verbs (you think, I can't believe, I mean). Collectively, these features put the focus not just on the topic of discussion but also on the subjective experiences of the speakers. Buffy, Willow, and Kendra commonly frame their speech in first person statements (I'm not loving, I'd bet, I can't believe) which adds an emotional element to their comments, whereas Giles' speech here is largely impersonal.

While the female characters tend to approach conversations from a far more emotional orientation in general, Buffy's dialogue is often a more extreme example of this. In many cases, this type of characterization might contribute to a portrayal of women as weak or irrational in comparison to men. However, on Buffy the traditionally feminine is portrayed as powerful. While Giles and the largely male Watcher's Council he represents possess arcane knowledge, it is Buffy with her instinct, intuition, and empathy who holds the real power. As the series progresses, Buffy rejects the patriarchal authority of the Watcher's Council and eventually Giles, as she realizes she can be the Slayer 
without the guidance of a Watcher. In the following scene from the episode "Graduation Day, Part 1," Buffy informs Wesley, a representative of the Watcher's Council, that she will no longer be working for them. The features of involved production in Buffy's speech are in bold.

Wesley: The Council's orders are to -

Buffy: $\quad$ Orders? I don't think I'm gonna be taking any more orders. Not from you. Not from them.

Wesley: You can't turn your back on the Council.

Buffy: They're in England! I don't think they can tell which way my back is facing.

Wesley: Giles, talk to her.

Giles: I've nothing to say just now.

$$
\text { [...] }
$$

Buffy: $\quad$ Go and tell them that until the next Slayer shows up they can close up shop. I'm not working for them anymore.

Wesley: Don't you see what's happening? Faith poisoned Angel to distract you, to keep you out of the Mayor's way. And it's working. We need a strategy to -

Buffy: I have strategy. You're not in it.

Wesley: $\quad$ This is mutiny.

Buffy: I like to think of it as graduation. 
Buffy uses many features of involved production here, which are often interpreted as indications of tentativeness or weakness. Nevertheless, her speech is portrayed as highly assertive and powerful in this scene. Clearly the emphasis is on her personal assessment of the situation and her choice to reject the council's authority and regain control over her own life and her identity as the Slayer. This is expressed through her use of private verbs (I don't think, I like to think) and frequent use of first and second person pronouns. She uses possibility modals to show her disdain for the council (they can tell, they can close up shop) and uses analytic negation repeatedly and forcefully to make her renunciation clear (not from you, not from them). Buffy's speech in this scene exemplifies how the show takes characteristics often associated with femininity, in this case the use of features of involved production, and presents them as strong and powerful. When Buffy starts a line with I don't think she is not expressing uncertainty, but rather she is making her desires, which the council has largely ignored, the central focus. She uses the features of involvement to claim her identity as the Slayer as her own, as opposed to a tool to be manipulated by the men of the Watcher's Council. This demonstrates how the features associated with involvement can be used to achieve diverse communicative functions and ties in to the show's theme of female empowerment.

\subsection{Differences in Dialogue Written by Female and Male Scriptwriters}

The second research question asked whether female and male scriptwriters portrayed female and male language differently in Buffy in terms of the use of features associated with involvement. The results of the two-way ANOVA revealed that there was no significant difference in the way that male and female scriptwriters portrayed male and 
female language. Table 4.1 above displays the results of the two-way ANOVA showing that there were no significant differences in dialogue based on scriptwriter gender and that there was no interaction between the variables of scriptwriter gender and character gender. The mean Dimension 1 score for female dialogue written by female scriptwriters was 42.8, while the mean Dimension 1 score for female dialogue written by male scriptwriters was 41.1. Similarly, the mean Dimension 1 score for male dialogue written by male scriptwriters was 34.5 , while the mean Dimension 1 score for male dialogue written by female scriptwriters was 34.0.

The lack of difference due to scriptwriter gender shows that the scriptwriters were highly consistent in their portrayal of the characters on the show in terms of their use of the features of involvement. A comparison of samples from Buffy's speech written by female and male scriptwriters illustrates the continuity in her linguistic characterization across episodes. The first sample is taken from the episode "Witch," written by a female scriptwriter. Buffy is making the case to Giles that she should be allowed to try out for the cheerleading squad. The second sample is from the episode "Faith, Hope, and Trick," written by a male scriptwriter. Buffy's school principal, who acts as one of her nemeses in early seasons, has just been forced to allow her to come back to school after expelling her. The features of involvement are in bold. 
Example 1: Female scriptwriter

Buffy: I'll still have time to fight the forces of evil, okay? But I want to have a life. I want to do something normal. Something safe.

Example 2: Male scriptwriter

Buffy: $\quad$ So, I'm really back because the School Board overruled you... wow, that's like having your whole ability to do this job called into question when you think about it.

Buffy's voice is consistent throughout the two examples. She uses discourse particles (okay, so), contractions, first and second person pronouns, and present tense verbs in both samples, as well as indefinite pronouns in the first and demonstrative pronouns and the pronoun it in the second. These brief excerpts demonstrate how Buffy's speech reliably makes use of features of involvement to frame often serious issues in a casual, humorous manner.

A likely explanation for the finding that there was no difference based on scriptwriter gender is the explicit goal the writers had to keep the characters' styles consistent. As Espenson (n.d.), one of the scriptwriters, explained, the team of writers worked collaboratively on each episode during the initial planning stages before the individual credited writer of an episode would take the general outline built by the team and use it to write the actual scenes and dialogue. As noted in chapter 3, she further stated that the writers intentionally aimed to write in the same style and keep the characters and show as consistent as possible from episode to episode. The results of the MD analysis indicate that they were extremely successful at writing the characters' dialogue in a 
consistent manner, at least in terms of their use of the features of involved production. Given the central theme of female empowerment on the show and the show's stance that traditionally feminine qualities can be powerful, it makes sense that the scriptwriters would take care to portray the characters' speech in a way that expresses those values by showing aspects of feminine speech in a positive light.

\subsection{Variability in Buffy Dialogue Based on Context}

While the characters' use of the features of involvement was consistent overall, there was also variability within the female and male language on the show. Figure 4.2 shows the range of Dimension 1 scores for both female and male dialogue. The scores for female dialogue are in bold to highlight the contrast with the scores for male dialogue. 
Involved

Production

Informational

Production

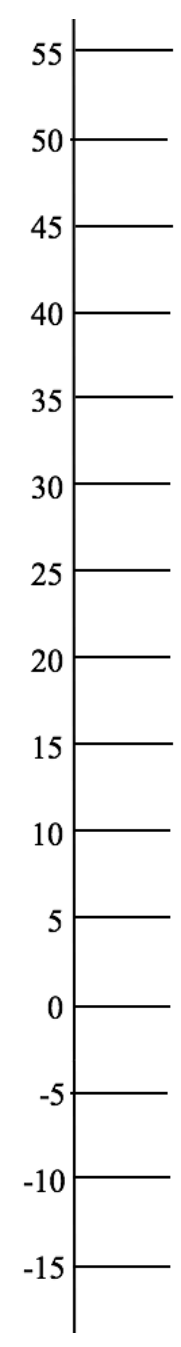

High score for female language in Buffy (54.6)

High score for male language in Buffy (44.3)

Mean female language in Buffy (42.0)

Mean male language in Buffy (34.2)

Low score for female language in Buffy (33.9)

Low score for male language in Buffy (22.6)

Figure 4.2 Range of Dimension 1 scores for male and female language in Buffy the Vampire Slayer

In order to explore the dialogue variability, I considered how contextual factors, such as the situation in a specific episode or scene or the social relationships between characters, influenced language use on the show. There was a consistent pattern among the episodes with the highest Dimension 1 scores; Many of them feature some of the most important and dramatic plotlines in the series, often with events of great emotional importance for the characters. Among the files with the highest Dimension 1 scores were 
episodes in which Buffy's boyfriend Angel loses his soul and becomes evil (“Innocence"), Willow's girlfriend Tara is murdered and Willow loses control of her powers as a witch trying to enact vengeance on her killer, nearly destroying the world ("Villains"), and Willow comes out as a lesbian ("New Moon Rising").

The following dialogue is from the episode "Villains," which has one of the most extreme Dimension 1 scores in the corpus. Warren, the leader of a group of misogynistic young men intent on harming Buffy and exploiting women, has just shot and killed Willow's girlfriend Tara after shooting Buffy, who has been healed by magic. In this scene, Willow tells Buffy and Xander that Tara is dead and suggests that she is going to use witchcraft to kill Warren out of revenge. Buffy objects because the Slayer is not supposed to kill humans, only demons, and she fears that Willow will lose herself to the forces of dark magic if she uses them to kill a human. Features of involvement are in bold.

Buffy: You're angry. I am too. What Warren did, there's no excuse, butWillow: He hit Tara. [stunned silence]

Willow: When he shot you, he hit her too. Upstairs. In my room.

Buffy: Oh my God-

Willow: [bitterly] Guess the last shot was the charm.

Xander: She's dead?

Willow: She's dead. And now he's dead.

Buffy: $\quad$ No...Oh God, Tara... 


\author{
Xander: $\quad$ Christ, Will. Why didn't you say anything? \\ Willow: I'm busy \\ Buffy: $\quad$ No. Come on, stop- \\ Willow: Don't- \\ Buffy: We love you. And Tara. But we don't kill humans. This isn't the \\ way- \\ Willow: How can you say that? Tara is dead. \\ Buffy: $\quad$ I know...And I...I can't believe... anything. Not what happened, \\ not what you must be going through. But if you do this Warren \\ destroys you too.
}

The focus of this scene is on the characters' emotional responses to Tara's death and this is reflected in the language that they use. There is a great deal of commentary on their emotional states using first and second person pronouns and often using be as the main verb (you're angry, I am too, we love you). The characters ask each other clarifying wh questions to try to get a better grasp on a situation that is shocking and painful (Why didn't you say anything? How can you say that?). Buffy, in particular, uses a combination of first person pronouns, private verbs, possibility modals, and indefinite pronouns to express her incredulity at the situation as she tries to process it (I know, I can't believe...anything). Although Willow is sharing new information with Buffy and Xander, the emotional impact of the information on the characters is portrayed as much more important than the details of Warren's attack on Tara. While the characters in general, and the female characters in particular, typically use language that falls on the 
involved end of Dimension 1, this scene illustrates how events of great emotional significance can lead to more extreme uses of the features of involvement.

In addition to the situational context of a scene, the different roles that the characters take on throughout the series and how those roles impact their social relationships with one another also influenced the characters' use of the features of involvement. A consistent example of this can be found in Giles, who generally uses much more of the features of informational production than the other characters as he advises them in their battles against demons and other creatures and is typically portrayed as more stoic than the others. However, as the series progresses and Buffy and Giles become closer over the years, and especially after Buffy's mom dies unexpectedly, Giles transitions into more of a father role in Buffy's life. They have more interactions that center on their emotional relationship rather than the enemies they are fighting. The scene below from the episode "Spiral" depicts Buffy and Giles having more of a fatherdaughter moment than a Watcher-Slayer moment. Giles has just been seriously wounded in battle, leading Buffy to question her tactical choices as she fears losing Giles. The features of involvement are in bold.

Buffy: I'm sorry.

Giles: $\quad$ For what?

Buffy: We should have stayed. If we had, none of this -

Giles: Don't. You did... what was necessary. What I've always admired. Buffy: $\quad$ Running away? 
Giles: $\quad$ Being able to place your heart above all else. I'm so proud of you. How far you've come. You're everything a Watcher - everything I could have hoped for...

As Buffy begins to question her leadership decisions that resulted in Giles' injury, he stops her and steers the conversation toward his feelings for her. They use contractions throughout and Giles uses a series of first and second person pronouns to express to Buffy how much she means to him. He even clarifies that he is addressing her not as her Watcher, but simply as himself, someone with a personal as opposed to professional relationship to her. Giles tells Buffy that he is proud of her, using the amplifier so for added intensity, as a father would a daughter. This scene shows how the social roles that characters take on influence their language use and is also one of many examples from the show of a male character speaking in a more involved manner.

\subsection{Summary of results}

The current study has several main findings. First, female dialogue on Buffy the Vampire Slayer was portrayed as having significantly more features of involvement than male dialogue. While on the surface this may seem contradictory to the show's feminist message because it suggests that the show portrayed men and women in stereotypical ways, it actually corresponds to the show's perspective that the feminine can be powerful. Thus, female characters are shown using the features of involvement in ways that demonstrate strength rather than weakness. The male characters also speak in a highly involved manner, though to a lesser extent than the female characters. Furthermore, the 
results also showed that male and female scriptwriters can be consistent in their portrayal of male and female characters' speech with regard to the features of involvement. Finally, just as with real people, there was variability within the language that male and female characters used on the show based on the situation and the social relationships between characters. This finding highlights the importance of considering the context of interactions in studies of gendered language use. 


\section{Chapter 5: Conclusion}

This chapter begins with an overview of the main findings of the study in Section 5.1, followed by a comparison with previous studies in Section 5.2. Section 5.3 describes the study's implications for sociolinguistic research into gender representation in the media, as well as potential applications to media literacy and language pedagogy. Next, Section 5.4 addresses the limitations and provides ideas for future research. Finally, Section 5.5 concludes with the main contributions of the study.

\subsection{Summary of findings}

As mentioned in chapter 4, the study has several main findings. The first is that female dialogue was more highly involved than male dialogue on Buffy. The show appeared to use character dialogue as one way of expressing one of the main ideas of the series: that qualities traditionally associated with femininity can be powerful. Buffy is portrayed as very feminine and one aspect of that is her use of the features of involvement in her speech. The social and personal orientation that these features give her speech is not shown as a weakness, rather she is portrayed as emotionally intelligent, self-aware, and compassionate, characteristics which all factor in to her success as the Slayer and as a leader. Further, men are also shown to speak in a highly involved manner, although to a lesser extent than the female characters. Men on the show are often valued for their emotional contributions in relationships, more so than traditionally masculine qualities such as physical strength. The show challenges the notion of traditional masculinity by showing its ineffectiveness in comparison to more well-rounded men. Traditionally 
feminine traits are depicted as human qualities that should be valued in both women and men.

Another finding is that there was no significant difference between how male and female scriptwriters wrote the characters' use of features of involvement. This shows that men and women can write consistently in different styles that don't necessarily correspond to traditional gendered speech patterns. This finding is somewhat surprising given that previous research (see Biber \& Burges, 2001) indicated that male and female scriptwriters showed a stylistic preference for dialogue that corresponds to the stereotypical speech patterns of their own gender. The consistency among the writers on Buffy likely reflects the explicit work that they put into stylistic uniformity and does not necessarily suggest that scriptwriters on other shows are able to write character dialogue so consistently in terms of the use of features of involvement. The feminist message that the show means to convey also likely encouraged the scriptwriters on Buffy to craft dialogue that reflects this message. On shows with a less explicit social or political orientation, it is not clear to what extent scriptwriters consider how the language characters use can promote or challenge gender norms.

\subsection{Comparison with previous studies}

Rey's (2001) study of Star Trek dialogue found that in the original series female dialogue was drastically more involved than male dialogue, which was portrayed as highly information oriented. In later series, the male dialogue became more highly involved as men were shown taking on more care taker roles in their family lives and the female dialogue became less involved than the male as female characters were shown in 
leadership roles. Rey viewed this as an indication of changing gender roles in society, as it was becoming more socially acceptable for men and women to take on roles traditionally associated with the opposite gender.

Buffy takes a very different approach to women's empowerment. In this case, both female and male dialogue is very highly involved. The female characters' dialogue is even more highly involved than that of the female characters in classic Star Trek. In some ways this might appear to contradict the feminist vision of the show. However, as discussed above, the show's stance is that female empowerment involves acknowledging and valuing traditionally feminine qualities and recognizing how important it is for leaders to have these qualities. It makes sense then that all of the characters on Buffy make extensive use of the features of involvement rather than showing a shift toward more informational speech as seen in the later Star Trek series. The age of the characters and context of the shows is also relevant here, as the characters on Star Trek often have more formal relationships as comrades working on a space craft, while many of the characters on Buffy are teenage friends. The contrast in the use of features of involvement may also reflect a difference in perspective between second and third wave feminism, in which the former focused on women's equality in the workplace and argued that women also possess qualities more traditionally associated with men while the latter reclaimed and celebrated the feminine, arguing that it is not inherently less valuable than the masculine (Mann \& Huffman, 2005).

The findings also differed from Biber and Burges' (2001) study of dialogue from plays, which explored the effect of scriptwriter gender on the level of involvement. Biber and Burges found that female writers wrote more highly involved dialogue for characters 
of all genders, while male writers wrote less highly involved dialogue for characters of all genders. They argued that this finding partially supports the conclusions of earlier studies of gendered language use which found that female speakers used more features of involvement and are more tentative than male speakers, based on the female writers' stylistic preference for involved speech. On the other hand, the current study found that the male and female scriptwriters on Buffy were quite consistent in their use of the features of involvement in male and female dialogue. They both portrayed female speech as very highly involved and male speech as less highly involved than female speech, but still on the involved end of the spectrum. This is likely due, in large part, to an intentional effort to write the characters consistently and in a way that reflects the values of the show. However, it does suggest that male and female writers can deliberately craft dialogue in varying styles as opposed to simply mirroring traditional gendered styles of speaking.

\subsection{Applications and implications}

The current study has implications for sociolinguistics and researchers studying gendered language use. Some studies of gendered speech treat many of the features of involvement, such as hedges and modals, as expressions of uncertainty, tentativeness, or even weakness. This seems to reflect a priori assumptions about the use of those features without necessarily taking into account how speakers are actually using them in context. More recent approaches to studying gendered language use prioritize the role of context and treat gendered speech patterns as linguistic resources that speakers can utilize for various purposes. The findings of the current study highlight the importance of 
considering interactional context and the diverse communicative functions that linguistic features can have in investigations of gendered speech. As the dialogue in Buffy shows, the features of involvement can be used to express confidence and assertiveness and characters can be powerful and use those features. Too often features and qualities that become associated with women take on negative connotations, so researchers must be mindful not to assume that these features can express only one meaning. The characterization of the features of involvement as an expression of weakness is suspect, especially considering how they work together to build rapport among speakers which is a very positive, prosocial use. It is telling that there has been work examining why women seem to use these features more and framing this usage as a problem, but there has not been the same level of interest in exploring how the use of features of informational production in male speech can be socially inept and distancing.

The finding that female and male scriptwriters were able to write female and male characters in different styles consistently on the show is also relevant to research on gendered language use. Research in this area is demonstrating more and more the complexity of gendered speech and how there is not just one style of female or male speech. It does seem to be the case that there are normative styles of female and male speech that speakers can recognize, but individual speakers are able to draw from these styles as they choose for different purposes in different contexts. Both male and female scriptwriters on Buffy were able to craft dialogue that was highly involved and less highly involved in order to portray characters in various ways that reinforce the themes of the show. The dialogue also reflected the variability that is seen within male and female 
dialogue, which underscores the importance of considering differences within gender groups in addition to differences between them.

Additionally, the findings of this study have applications in various educational settings. Curricula that focus on the development of media literacy, which involves building the skills to access and critically evaluate media, can benefit from a discussion of gender representation and language use. Within the field of language pedagogy, critical language teaching takes the larger social and political context into account in the classroom and aims to help students develop critical thinking skills as well as language skills. Working with language learners to critically evaluate popular media can help them gain awareness of various linguistic features and their social functions. This practice can empower learners with the ability to engage with media in a thoughtful way that encourages reflection on their own values and those of the language community they are joining. For example, a teacher could present learners with dialogue samples from scripts of various genres that portray male and female characters in different ways and perhaps even play clips from the scenes in class. Then learners could compare and contrast how gender is represented in the different scripts, identifying how specific linguistic features contribute to the representation. This type of activity also provides an opportunity for teachers to demonstrate how multiple linguistic features work in tandem to communicate meaning and contribute to a character's overall portrayal.

\subsection{Limitations of the current study and ideas for future research}

At 230,300 words, the Buffy corpus is relatively small. In cases where compiling a complete corpus is possible, such as with a television series that is no longer on air and 
thus has a finite number of episodes, the ideal would be to include every episode in the corpus. Due to time constraints, the inclusion of every episode was not feasible for this thesis, but the corpus could easily be expanded and the study replicated. Another limitation of the study is the unquantifiable influence of the showrunner and others working on the show besides the credited author on the final scripts. While the credited authors wrote multiple drafts of the scripts themselves, they made changes based on feedback from the showrunners, who also had the freedom to make final changes before shooting. There is no way of knowing in this case exactly what changes were made to scripts and by whom. Future studies of television dialogue could try to separate out the influence of showrunners and others by obtaining all the drafts of scripts with the showrunner's notes or by specifically looking at how dialogue differs based on the identity of the showrunner.

Of course, this study also focuses on the dialogue of one television show. The genre and political orientation of the show are likely to influence the findings, so they cannot be generalized to all television shows. Future studies could examine different shows from a variety of genres in order to compare gender representation across multiple television genres. Extending this type of research to include shows that feature nonbinary and transgender characters would expand our knowledge of how various gender identities are portrayed. Additional studies of television dialogue using more qualitative methods could also further our understanding of gender representation in the media. It would be especially interesting to conduct a fully qualitative analysis of a show that has already been studied using MD analysis, such as Buffy or Star Trek, in order to compare the findings. 
The current study also found that context plays an important role in the use of features of involvement. Future studies could focus their analysis specifically on the role of context in portrayals of male and female speech. Are men or women depicted in different contexts and roles from one another, leading them to use different styles of language or are men and women shown to use language in different ways even when they appear in similar contexts and roles? Workplace dramas that portray professional men and women working side by side in the same environment, such as doctors on Grey's Anatomy or political advisors in The West Wing, would make interesting potential sources of data.

\subsection{Conclusion}

The current study explored the effects of character gender and scriptwriter gender on the use of features of involved production in dialogue in Buffy the Vampire Slayer. The analysis revealed that female speech was portrayed as much more highly involved than male speech, although both fell on the involved end of Dimension 1. It also showed that male and female scriptwriters were highly consistent in their representations of male and female speech. The show challenged gender norms by showing how traditionally feminine qualities can be powerful, which was represented in part through Buffy's use of the features of involvement in ways that express confidence and leadership. The men on the show, who for the most part are not as physically strong as Buffy, are valued for their social and emotional contributions and are also shown using many features of involved production. Media representations of gender have the power to reinforce or subvert dominant gender norms, so the ability to critically evaluate these representations plays an 
important role in the fight for gender equity. Shows like Buffy that present a strong vision of female empowerment can have a profound influence on viewers, particularly young girls who are still developing their perspectives on womanhood and the possibilities for women in society. 


\section{References}

Adams, M. (2003). Slayer slang: A Buffy the Vampire Slayer lexicon. Oxford: Oxford University Press.

Adams, M. (Ed.). (2006). Beyond slayer slang: Pragmatics, discourse, and style in Buffy the Vampire Slayer [Special Edition]. Slayage, 5(20).

Al-Surmi, M. (2012). Authenticity and TV shows: A multidimensional analysis perspective. TESOL Quarterly, 46(4), 671-694.

Bergvall, V. L. (1996). Constructing and enacting gender through discourse: Negotiating multiple roles as female engineering students. In V. L. Bergvall, J. M. Bing, \& A. F. Freed (Eds.), Rethinking language and gender research: Theory and practice (pp. 173-201). New York: Longman.

Bertoli-Dutra, P. (2014). Multi-dimensional analysis of pop songs. In T. B. Sardinha \& M. V. Pinto (Eds.), Multi-dimensional analysis, 25 years on: A tribute to Douglas Biber (pp. 149-175). Philadelphia, PA: John Benjamins North America.

Biber, D. (1988). Variation across speech and writing. Cambridge: Cambridge University Press.

Biber, D. \& Finegan, E. (1993). ARCHER-1: A representative corpus of historical English registers version 1. Available at https://www.projects.alc.manchester.ac.uk/archer/

Biber, D., \& Burges, J. (2001). Historical shifts in the language of women and men: Gender differences in dramatic dialogue. In S. Conrad \& D. Biber (Eds.), Variation in English: Multi-dimensional studies. Harlow: Longman. 
Biber, D. (2006). University language: A corpus-based study of spoken and written registers. Amsterdam: John Benjamins.

Biber, D., Davies, M., Jones, J.K., \& Tracy-Ventura, N. (2006). Spoken and written register variation in Spanish: A multi-dimensional analysis. Corpora, 1(1), 1-37.

Billson, A. (2005). Buffy the Vampire Slayer: A critical reading of the series. London: The British Film Institute.

Brown, P. \& Fraser, C. (1979). Speech as a marker of situation. In H. Giles \& K. Scherer (Eds.), Social markers in speech (pp. 33-62). Cambridge: Cambridge University Press.

Byers, M. (2003). Buffy the Vampire Slayer: The next generation of television. In R. Dicker \& A. Piepmeier (Eds.), Catching a wave: Reclaiming feminism for the $21^{s t}$ century (171-187). Boston: Northeastern University Press.

Chafe, W. (1982). Integration and involvement in speaking, writing, and oral literature. In D. Tannen (Ed.), Spoken and written language: Exploring orality and literacy (pp. 35-54). Norwood, New Jersey: Ablex Publishing Corporation.

Coates, J. (2015). Women, men, and language: A sociolinguistic account of gender differences in language. London: Longman.

Conrad, S., \& Biber, D. (2001). Multi-dimensional methodology and the dimensions of register variation in English. In S. Conrad \& D. Biber (Eds.), Variation in English: Multi-dimensional studies (pp. 13-42). Harlow: Longman.

Conrad, S. (2018). The use of passives and impersonal style in civil engineering writing. Journal of Business and Technical Communication, 32(1), 38-76. 
Early, F. H. (2004). Staking her claim: Buffy the Vampire Slayer as transgressive woman warrior. The Journal of Popular Culture, 35(3), 11-27.

Espenson, J. (n.d.). The writing process. Retrieved from http://www.janeespenson.com/writing_process.php

Ervin-Tripp, S. (1972). On sociolinguistic rules: Alternation and co-occurrence. In J. Gumperz \& D. Hymes (Eds.), Directions in sociolinguistics (pp. 213-250). New York: Holt, Rinehart, and Winston.

Hall, K. (1995). Lip service on the fantasy lines. In K. Hall \& M. Bucholtz (Eds.), Gender articulated: Language and the socially constructed self (pp. 183-216). New York: Routledge.

Holmes, J. (1995). Women, men and politeness. London: Longman.

Hymes, D. (1974). Ways of speaking. In R. Bautman \& J. Sherzer (Eds.), Explorations in the ethnography of speaking (pp. 433-452). Cambridge: Cambridge University Press.

Jenkins, A. \& Stuart, S. (2003). Extending your mind: Non-standard perlocutionary acts in "Hush." Slayage, 3(10).

Kanoksilapatham, B. (2007). Rhetorical moves in biochemistry research articles. In D. Biber, U. Connor, \& T. A. Upton (Eds.), Discourse on the move: Using corpus analysis to describe discourse structure (pp. 73-120). Amsterdam: John Benjamins.

Kendall, S. \& Tannen, D. (2001). Discourse and gender. In D. Schiffrin, D. Tannen, \& H. E. Hamilton (Eds.), The handbook of discourse analysis (pp. 548-567). Malden, MA: Blackwell Publishers. 
Kim, Y. J., \& Biber, D. (1994). A corpus-based analysis of register variation in Korean. In D. Biber \& E. Finegan (Eds.), Sociolinguistic perspectives on register (pp. 157181). Oxford: OUP.

Lakoff, R. (1973). Language and woman's place. Language in Society, 2(1), 45-80.

Lakoff, R., \& Tannen, D. (1984). Conversational strategy and metastrategy in a pragmatic theory: The example of scenes from a marriage. Semiotica,, 49(3), 323346.

Lemish, D. (2012). Gender: Representation in the media. In W. Donsbach (Ed.), The International encyclopedia of communication. Hoboken, NJ: Wiley \& Sons, Inc.

Lester, D. (2014). "Don't speak Latin in front of the books": Latin as the lingua franca of magic in Buffy the Vampire Slayer. Slayage, 12(40).

Levine, E. (2007). Buffy and the "new girl order": Defining feminism and femininity. In E. Levine \& L. Parks (Eds.), Undead TV: Essays on Buffy the Vampire Slayer (pp. 168-189). Durham: Duke University Press.

Lorber, J. (2011). The social construction of gender. In D. B. Grusky \& S. Szelenyi (Eds.), The Inequality reader: Contemporary and foundational readings on race, class, and gender (pp. 111-117). New York: Routledge.

Mann, S. A. \& Huffman, D. J. (2005). The decentering of second wave feminism and the rise of third wave. Science \& Society, 69(1), 56-91.

Milestone, K., \& Meyer, A. (2012). Gender and popular culture. Cambridge: Polity Press.

Murphy, B. (2010). Corpus and sociolinguistics: Investigating age and gender in female talk. Amsterdam: John Benjamins Publishing Company. 
Newman, M. L., Groom, C. J., Handelman, L. D., \& Pennebaker, J. W. (2008). Gender differences in language use: An analysis of 14,000 text samples. Discourse Processes, 45(3), 211-236.

Ono, K. A. (2000). To be a vampire on Buffy the Vampire Slayer: Race and ("other") socially marginalizing positions on horror TV. In E. R. Helford (Ed.), Fantasy girls: Gender in the new universe of science fiction and fantasy television (pp. 163-186). Lanham, MD: Rowman \& Littlefield Publishers, Inc.

Quaglio, P. (2009). Television dialogue: The sitcom Friends vs. natural conversation. Amsterdam: John Benjamins Publishing Company.

Rayson, P., Leech, G., \& Hodges, M. (1997). Social differentiation in the use of English vocabulary: Some analyses of the conversational component of the British National Corpus. International Journal of Corpus Linguistics, 2(1), 133-152.

Rey, J.M. (2001). Changing gender roles in popular culture: Dialogue in Star Trek episodes from 1966 to 1993. In S. Conrad \& D. Biber (Eds.), Variation in English: Multi-dimensional studies (pp. 138-156). Harlow: Longman.

Richardson, K. (2010). Television dramatic dialogue: A sociolinguistic study. Oxford: Oxford University Press.

Said, S. F. (2010). Interview with Joss Whedon by SF Said. Retrieved from https://web.archive.org/web/20100512141258/http://www.shebytches.com/SFSai dgb.html

Sanchez, A. (2019). Variation in female and male dialogue in Buffy the Vampire Slayer: A multi-dimensional analysis. Unpublished manuscript, Portland State University, Portland, OR. 
Sardinha, T. B. (2014). 25 Years later: Comparing internet and pre-internet registers. In T. B. Sardinha \& M. V. Pinto (Eds.), Multi-dimensional analysis, 25 years on: A tribute to Douglas Biber (pp. 81-105). Philadelphia, PA: John Benjamins North America.

Sardinha, T. B., Kauffman, C., and Acunzo C. M. (2014). Dimensions of register variation in Brazilian Portuguese. In T. B. Sardinha \& M. V. Pinto (Eds.), Multidimensional analysis, 25 years on: A tribute to Douglas Biber (pp. 35-79). Philadelphia, PA: John Benjamins North America.

Talbot, M. (2003). Gender stereotypes: Reproduction and challenge. In J. Holmes \& M. Meyerhoff (Eds.), The handbook of language and gender (pp. 468-486). Malden, MA: Blackwell Publishing Ltd.

Tannen, D. (1985). Relative focus on involvement in oral and written discourse. In D. R. Olson, N. Torrance, \& A. Hildyard (Eds.), Literacy, language, and learning: The nature and consequences of reading and writing (pp. 124-147). Cambridge: Cambridge University Press.

Tannen, D. (1990). Gender differences in topical coherence: Creating involvement in best friends' talk. Discourse Processes, 13(1), 73-90.

Tannen, D. (1991). You just don't understand: Women and men in conversation. London: Virago Press.

Wahoske, M. J. (n.d.) Nielson ratings for Buffy the Vampire Slayer, Angel, and Firefly. http://home.insightbb.com/ wahoskem/buffy.html

West, C. \& Zimmerman, D. (1983). Small insults: a study of interruptions in cross-sex conversations between unacquainted persons. In B. Thorne, C. Kramarae, \& N. 
Henley (Eds.), Language, gender, and society (pp. 102-117). Rowley, MA:

Newbury House.

Whedon Studies Association (2019). About the WSA. Retrieved from

https://www.whedonstudies.tv/about.html

Wilcox, R.V. \& Lavery, D. (2002). Introduction. In R. V. Wilcox \& D. Lavery (Eds.), Fighting the forces: What's at stake in Buffy the Vampire Slayer (pp. xvii-xxix). Lanham, MD: Rowman \& Littlefield Publishers, Inc.

Xiao, R. (2009). Multi-dimensional analysis and the study of World Englishes. World Englishes, 28(4), 421-450. 